\title{
Design of Automatic Hand Sanitizer with Temperature Sensing
}

\author{
Abhinandan Sarkar \\ Faculty of Electronics \\ Department of Computer Science and Technology \\ Luthfaa Polytechnic Institute, Durgapur(W.B)
}

\begin{abstract}
The design depicted shows the preventive measure that can be taken during the COVID-19 pandemic in the whole world. Sanitizers have become the most significant commodities right now. By the new rules and regulations given by WHO vigorous sanitization is needed to survive. The design gave the solution for the problem stated. The design introduces an automatic hand sanitizer and temperature sensing system, to keep the hand sanitized whenever a person wants to do it, without a contact with the sanitizing machine. The temperature sensor on touching gives the body temperature of the person.
\end{abstract}

Keywords:- Automatic hand sanitizer, Arduino, ultrasonic sensor, PIR sensors, TMP36, covid-19.

\section{INTRODUCTION}

Since December 2019 the world is under tremendous tension, the numbers are increasing day by day, and till date no vaccine has been full proved against the pandemic agent. Yes it is COVID-19, it was unknown to the race before it outbroke in Wuhan, China. Being from a large family, a continuous mutation is occurring, forbidding the researchers, microbiologist, pharmaceuticals to draw the line of conclusion on the vaccine.

Affecting the most prestigious countries in a chain ; China, Italy ,Spain , USA , India , Russia, [1] the virus has proved it's strength and subservient a technologically enhanced race. The race of homo-sapiens.

The policies taken worldwide has lessen its affect to some extent but could not eradicate it. Lockdown has economically weaken many nations, and testing of different medicines has also not proven to be satisfactory. The question now prevail is Life vs. Livelihood. The weaker section of the society is facing the hardship due to vigorous lockdown across the nations. Seeing the picture of
India, one of the most promising countries in technology, the labourers are rushing for a little piece of grain. The starving faces reveal the pain. Industries are in losses, workers are losing jobs, economical growth of the nation has taken a back seat, but it should be realised that a regular monitoring of body temperature and periodical hand sanitization can prevent the spread of the pandemic to the masses.

Keeping in mind, the situation worldwide, sanitization commodities should be installed in each and every corner of the sphere, be it an industry, a corporate office, an educational institute or an shopping mall.

In this research work, an automatic hand sanitizer with temperature sensing design prototype has been made.

\section{OBJECTIVES}

With the above stated aspects, the design has been done for easy installation of the hardware in every possible places across the globe .

The design encompasses few parameters to be calculated and taken as priority, such as -

$>$ Installation of temperature sensor.

$>$ Installation of LCD to display the sensed temperature.

$>$ Installation of ultrasonic and PIR sensors.

$>$ Installation of spray pumps/submersible pumps.

$>$ Synchronizing all the sensors with Arduino UNO R3 microcontroller.

The circuit connection should be done minutely to avoid any kind of fault while working of the device.

Proper safety measure has been taken to overcome any kind of fault in consideration of over-voltage, short circuit, excessive current flow etc. 


\section{COMPONENTS}

\begin{tabular}{|c|c|c|}
\hline SL. NO. & COMPONENT & QUANTITY \\
\hline 1 & Arduino Uno R3 & 1 \\
\hline 2 & $\begin{array}{c}\text { Ultrasonic Range Finder } \\
\text { (PING SEN136B5B) }\end{array}$ & 2 \\
\hline 3 & $\begin{array}{c}\text { DC Motor/Submersible } \\
\text { Spray Pump }\end{array}$ & 1 \\
\hline 4 & LCD 16 x 2 & 1 \\
\hline 5 & 250 kilo ohm Potentiometer & 1 \\
\hline 6 & 220 ohm Resistor & 1 \\
\hline 7 & Temperature Sensor [TMP36] & 1 \\
\hline 8 & LED RGB & 1 \\
\hline 9 & PIR sensor & 2 \\
\hline 10 & Piezo Buzzer & \\
\hline
\end{tabular}

Table 1:- shows the components used while designing the project.

\section{A. Component Description}

\section{Arduino UNO R3 -}

It is an open source microcontroller based computing platform used for easy programming and synchronizing of different analog and digital sensors and it is also capable of sending and receiving data over the internet. It is built up with 8-bit Atmel AVR or 32- bit Atmel ARM microcontrollers. It provides a comfortable design platforms for hobbyists, students and professional designers[2]. Figure 1 shows the ARDUINO UNO R3 pinout.

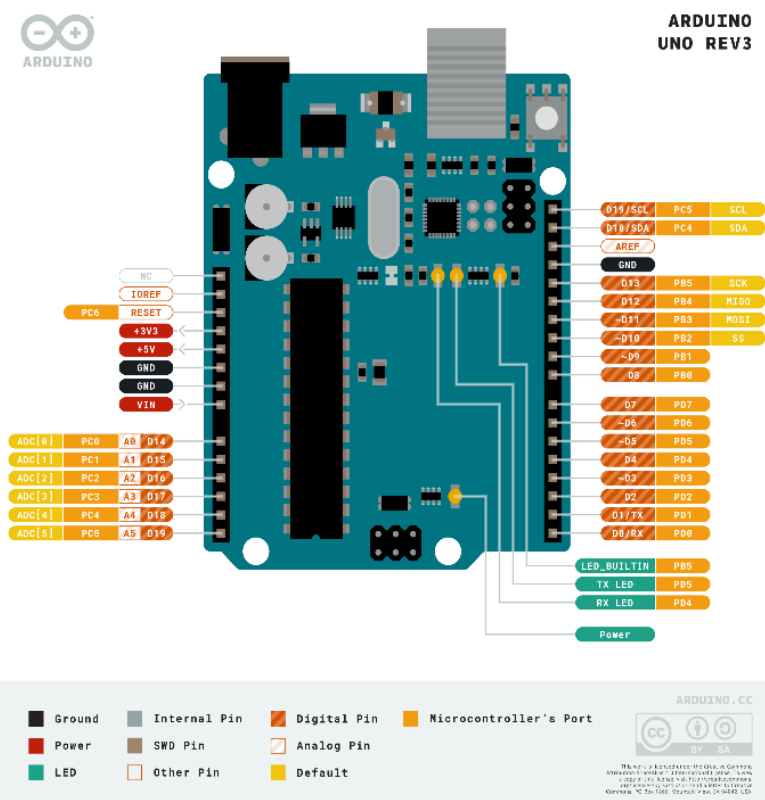

Fig 1:- Pinout of ARDUINO UNO R3 .

\section{Ultrasonic Range Finder (PING SEN136B5B)-}

The sensor has a range of $3 \mathrm{~cm}-400 \mathrm{~cm}$. The sensor operates by transmitting an ultrasound and receiving the echo as it bounces back against an obstacle after a certain time and calculates the distance of the object accordingly.[4] The sensors sends the ultrasound and senses the echo with the same pin SIG. Figure 2 shows an ultrasonic range finder(PING SEN136B5B).

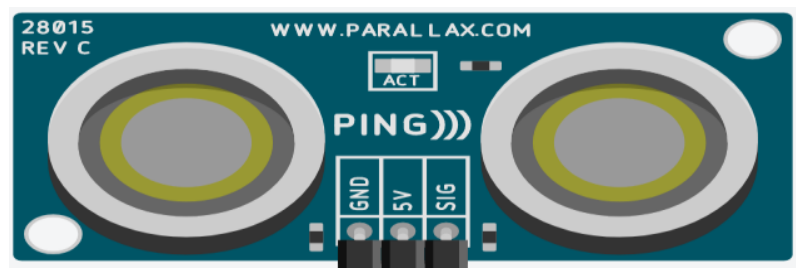

Fig 2:- Ultrasonic Range Finder (PING SEN136B5B).

DC Motor/ Submersible Spray Pump -

The motor/pump is used to spray the sanitizer on the hand after the sensors give required signal. It works at $3 \mathrm{v}$. Figure 3 shows a submersible spray pump.

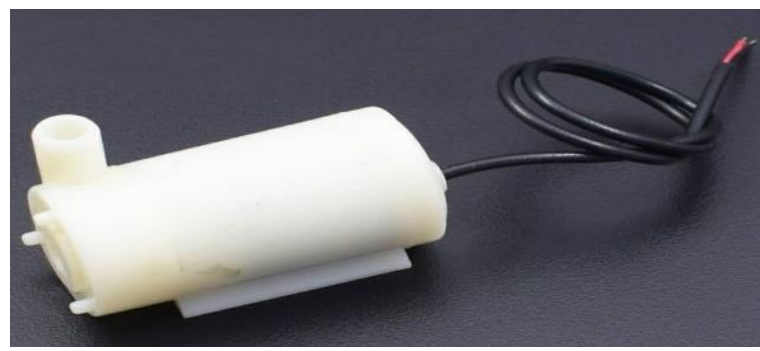

Fig 3:- Submersible spray pump.

\section{$L C D 16 \times 2$}

It is a liquid crystal display module that produces visible displays. It has 16 columns and 2 rows. Each character is displayed in $5 \times 7$ pixel matrix. $250 \mathbf{~ k ~ o h m ~}$ potentiometer is used to maintain the contrast of the display.220 ohm resistor is attached in anode terminal.[5]. Figure 4 shows a LCD $16 \times 2$.

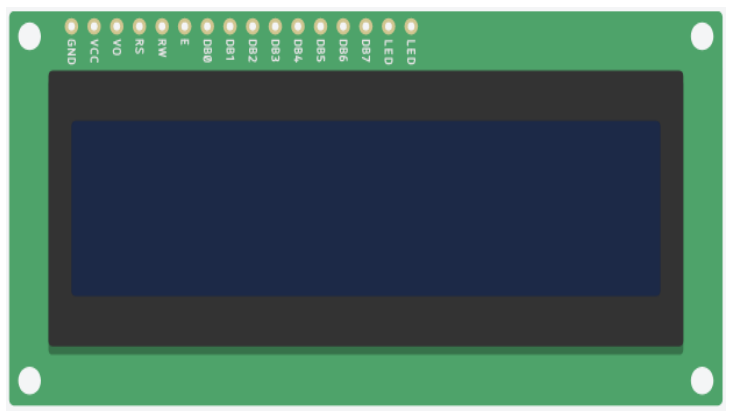

Fig 4:- LCD $16 \times 2$. 


\section{Temperature Sensor [TMP36] -}

The sensor works on the property of diode, as the temperature changes in the diode the voltage also changes at a constant rate. The analog input represents 0 as no voltage and 1023 as $5 \mathrm{v}$. According to the datasheet the sensor will give output $0-1.75 \mathrm{~V}$ over a range of $175^{\circ} \mathrm{C}(-$ $50^{\circ} \mathrm{C}-125^{\circ} \mathrm{C}$ ) that's depicts every $0.01 \mathrm{~V}=1^{\circ}$. [6]. Figure 5 shows TMP36.

Pin 1 - input voltage, Pin 2 - signal out, Pin $3-$ ground.

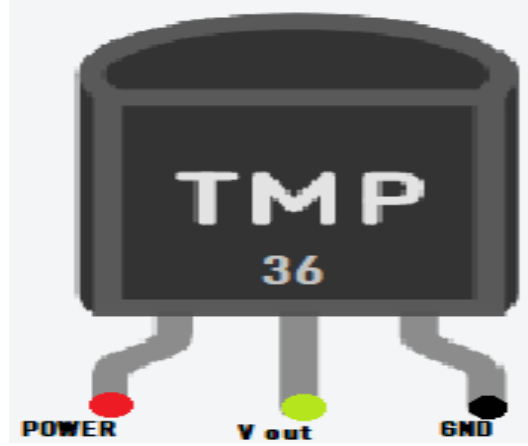

Fig 5:- Temperature Sensor [TMP 36].

\section{LED RGB -}

This led combines red, green, blue light to produce 16 million hues of light. But while operating in Arduino it is difficult to produce maximum of it. Unlike normal led it has four terminals, blue, green , cathode, red. Figure 6 shows RGB led.

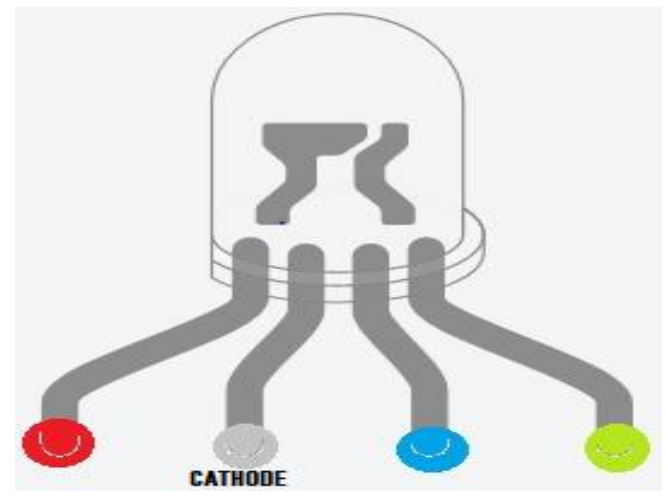

Fig 6:- RGB LED.

\section{PIR Sensor -}

Passive Infrared Sensors are used to sense motion and it almost detects human motion. The sensor is built using a pyroelectric sensor, it detects infrared signals, as every living body emits some level of radiation. The sensor divides the sensed signal into 2 halves, which is wired up, to cancel out each other and as one part senses the signal more or less, the output swings high or low.[7]. Figure 7 shows a PIR sensor.

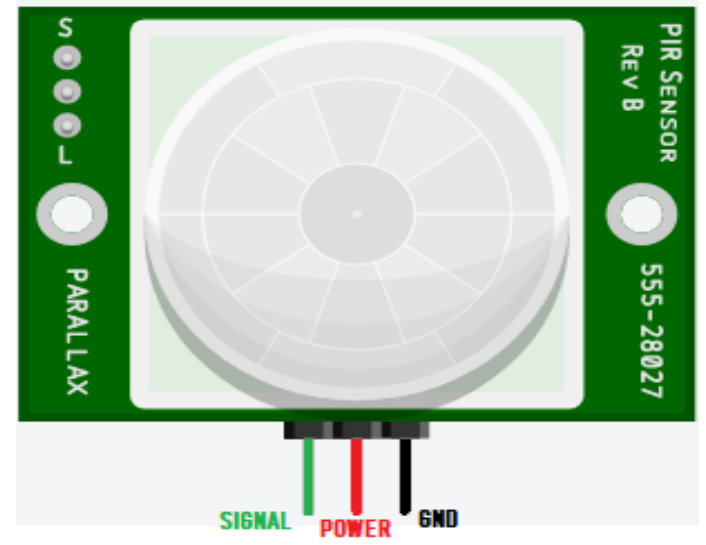

Fig 7:- PIR Sensor.

\section{Piezo Buzzer -}

It produces a tone when it is synchronized with other sensors or it is made to produce tone for particular purpose.

Figure 8 shows a piezo buzzer.

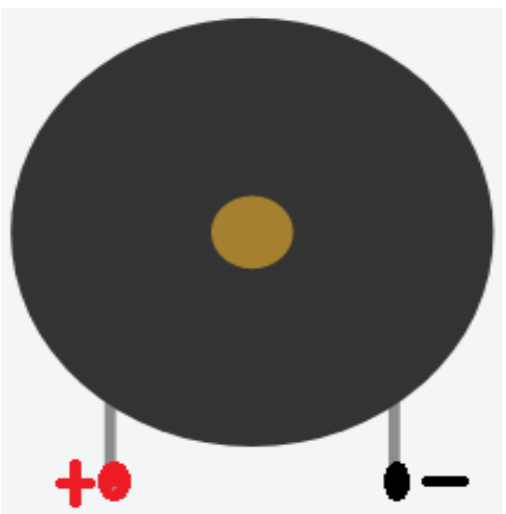

Fig 8:- Piezo Buzzer.

\section{Bread Board -}

It is a construction base used for making prototypes of different electronic circuits. It is a solderless base that ease in circuitry rectification. Figure 9 shows a bread board.

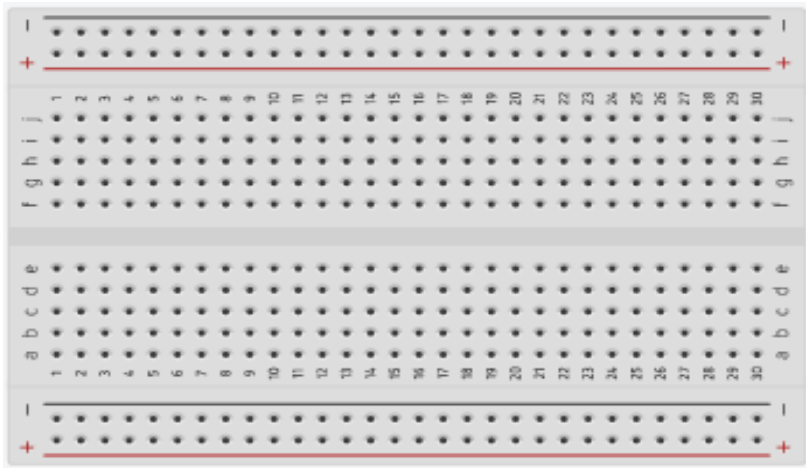

Fig 9:- Bread Board. 


\section{PROCESS FLOW}

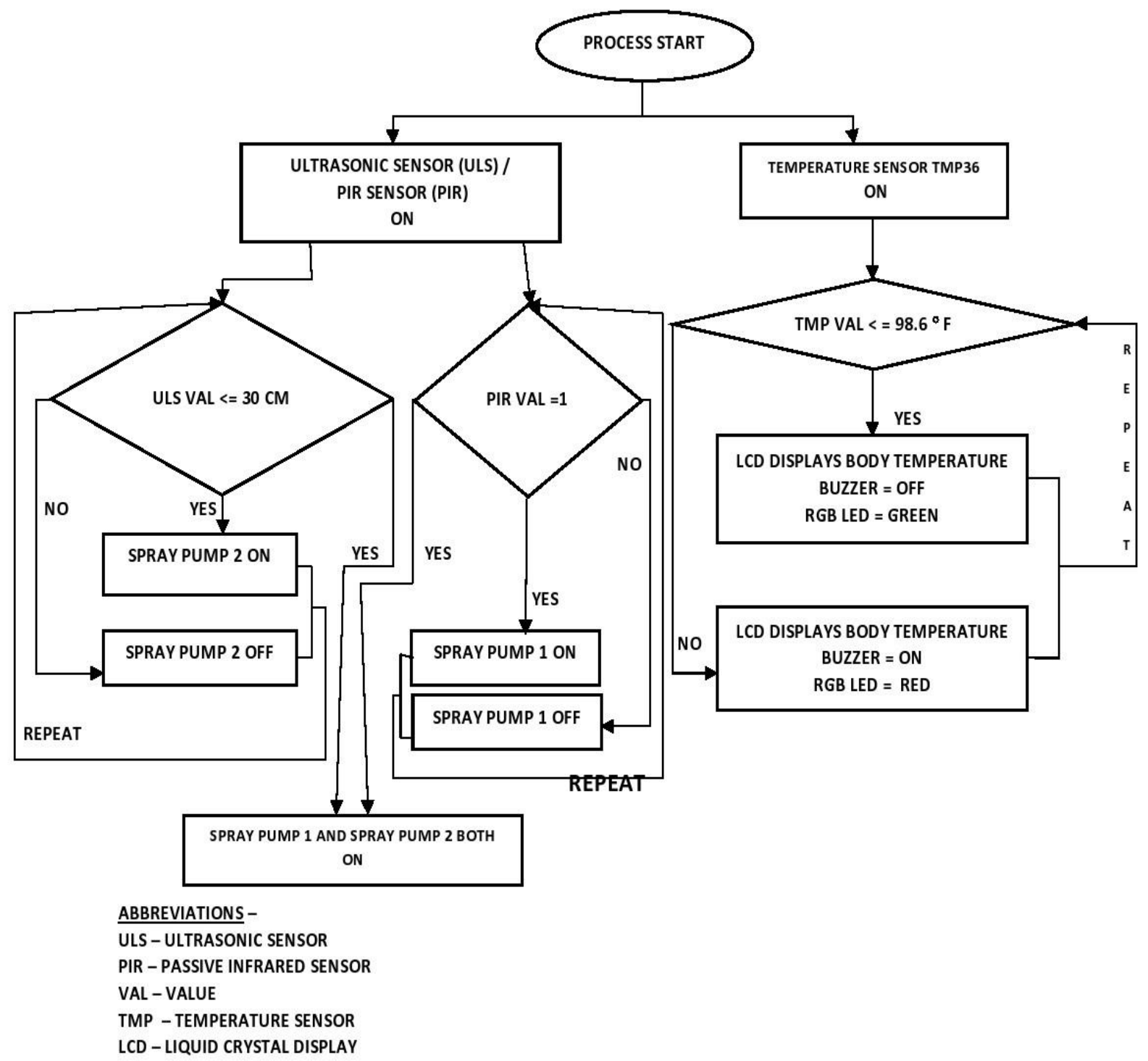

Fig 10

\section{METHODOLOGY}

As we switch on the device, the sensors attached to the Arduino gets activated. We have two systems to work simultaneously to each other. First the automatic sanitizer and secondly the contacted temperature sensing.

The ultrasonic sensor and PIR sensor is attached to the Arduino for detection of human/object ranging and motion respectively.

PIR sensor has a range of around $5 m-12 m$ and any detection in the specified range will activate the sanitizer and it will sanitize the surroundings with activation of spray pump 1 accompanied with a blower so that the sanitizer reaches the surrounding. The ultrasonic sensor on the other side has been specified with a range of less than $30 \mathrm{~cm}$, any movement especially hand near $(<30 \mathrm{~cm})$ the device will activate the spray pump 2 and the sanitizer reaches the hand through a small pipe.
The sanitization is done simultaneously with the activation of the sensors, keeping the particular region sanitize and free from virus or bacteria or any infectious agents.

The temperature sensor senses the body temperature of the person as soon as it is touched, and displays the temperature in ${ }^{\circ} \mathrm{F}$ in the lcd display(as it is programmed to convert ${ }^{\circ} \mathrm{C}$ to ${ }^{\circ} \mathrm{F}$ ). If the temperature sensed is above the normal body temperature $\left(98.6{ }^{\circ} \mathrm{F}\right)$ the buzzer starts alarming and the RGB led attached turns red, if the sensed value of the sensor is equal or below $98.6^{\circ} \mathrm{F}$ then the buzzer is off and the RGB led is green. Depicting a symbol of safe and safety.

A picturised prototype is shown below in figure 10 for the visualization of the device. 


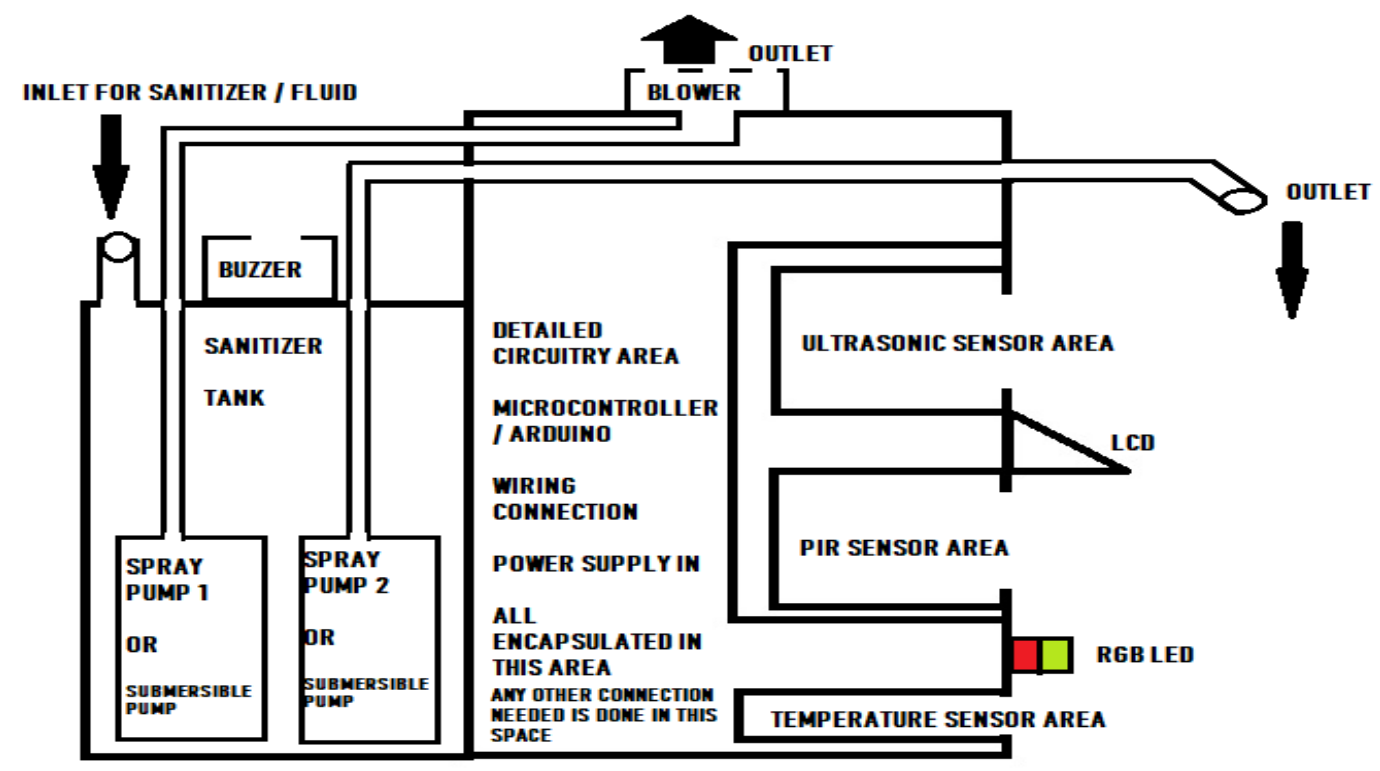

Fig 11:- Device model prototype.

The circuit is designed in TINKERCAD software, programming is done, simulated and made to a working schematic. Not taking power supply as a major concern, if needed relays can be attached to drive the motors/pumps attached in circuitry. The detailed schematic of the working circuit is shown below in figure 12

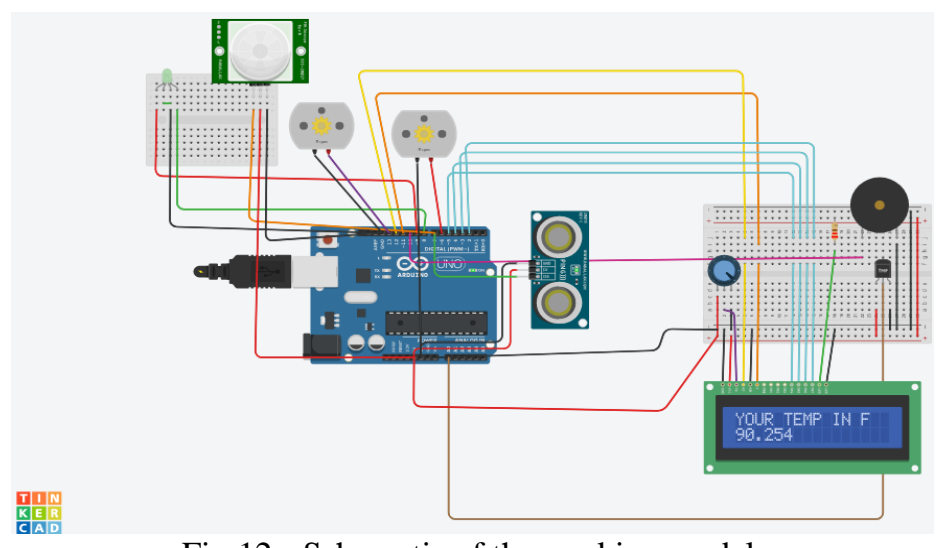

Fig 12:- Schematic of the working model.

\section{RESULT AND DISCUSSION}

Simulating the circuit at different instance we can see the working of two motors as there is a change of rpm in the motors while changing the sensor values. Checking for the led and buzzer signal while sensing temperature it can be seen that the led changes its colour and there is a radiating wave signal/tone through the buzzer.

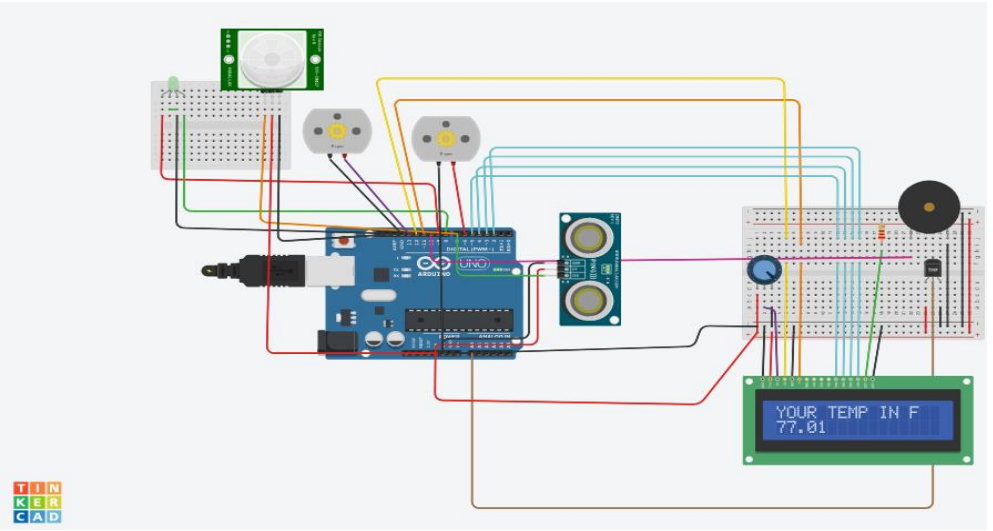

Fig 13:- Shows the led is green and buzzer is off as temperature is $77.01^{\circ} \mathrm{F}\left(<98.6^{\circ} \mathrm{F}\right)$. 


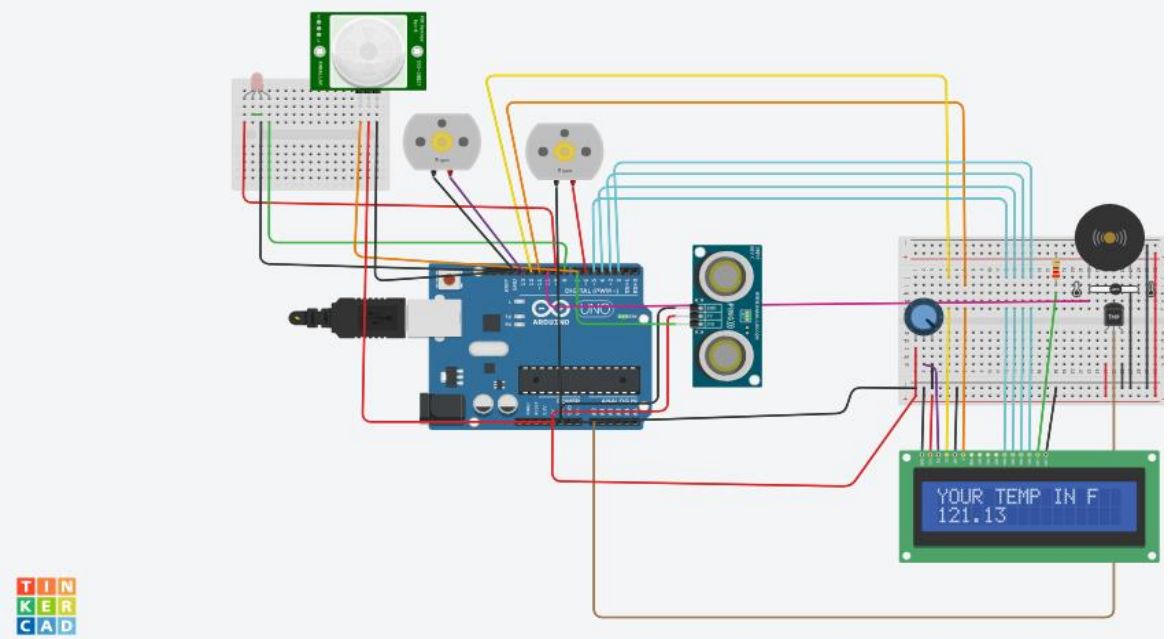

Fig 14:- Shows the led turns red and buzzer produces wave signal/tone as temperature changes to $121.13^{\circ} \mathrm{F}\left(>98.6^{\circ} \mathrm{F}\right)$.

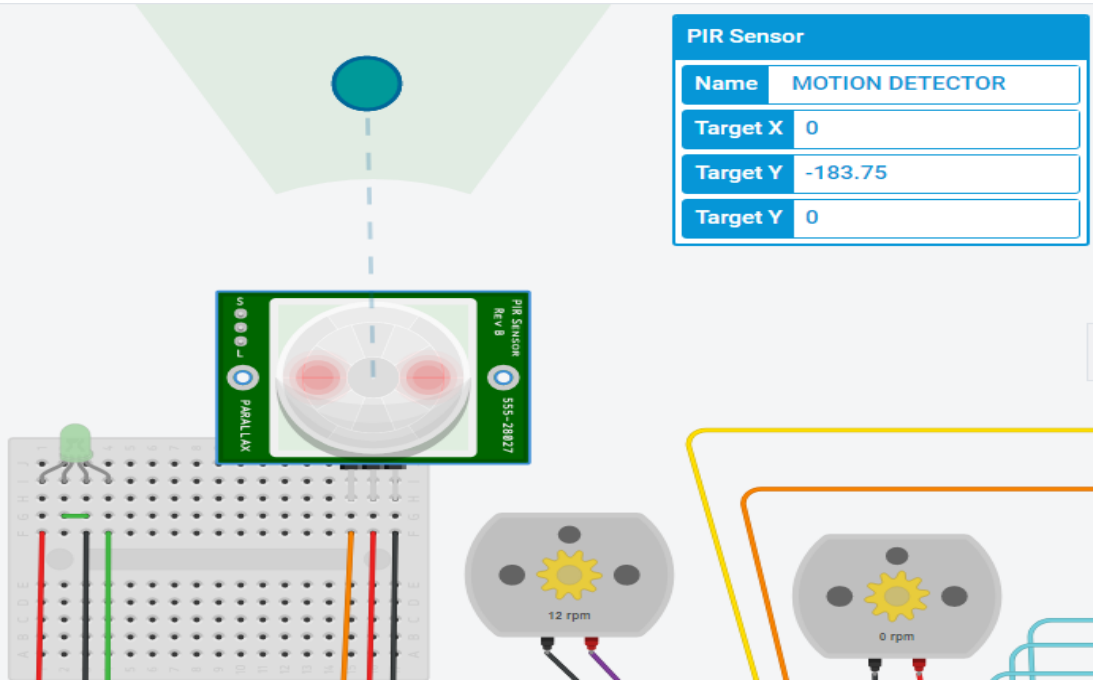

Fig 15:- Shows that spray pump/motor 1 runs with certain rpm as the PIR sensor gets activated.

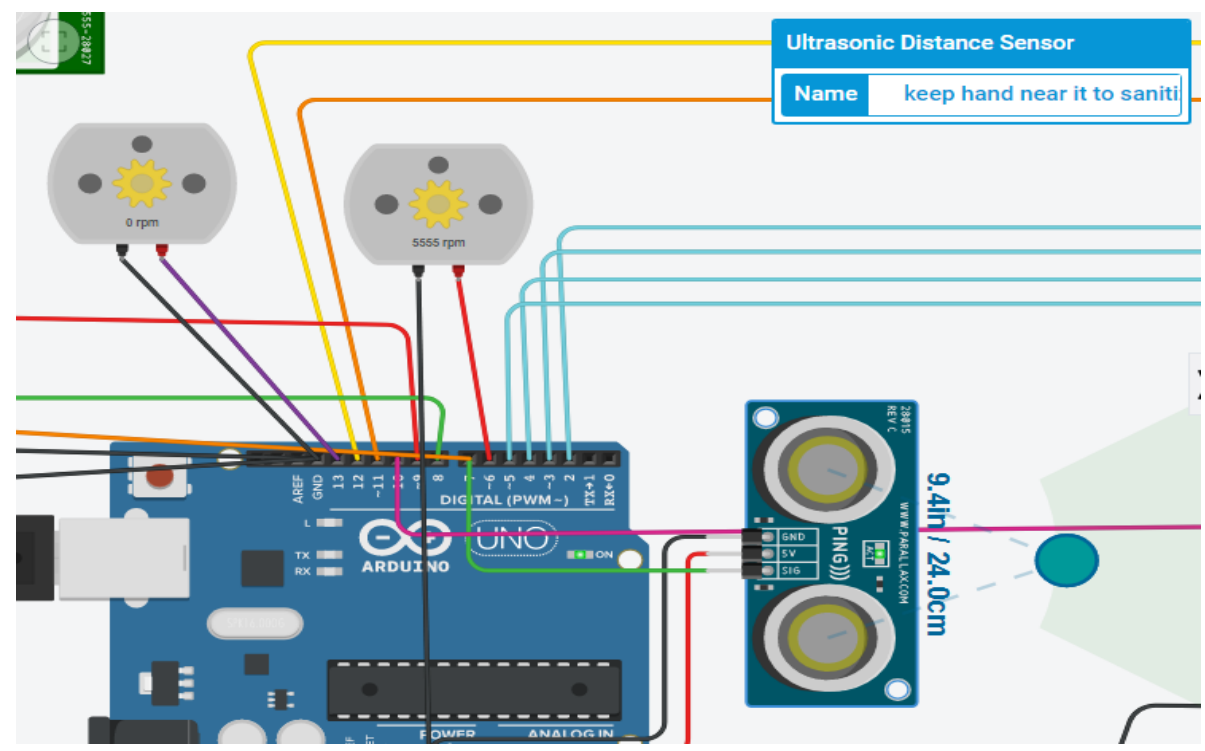

Fig 16:- Shows that spray pump/motor 2 runs with certain rpm as the Ultrasonic sensor gets activated. 


\section{CONCLUSION AND FUTURE SCOPE}

As stated earlier the device circuit is made in a software and simulated accordingly. While prototyping the hardware some power distribution to each module can be a hindrance, to overcome the problem, relays must be installed to drive the spray pumps/submersible pumps, so that the sensors, lcd and other minute modules get enough power supply from the inbuilt $5 \mathrm{~V}$ and $3.3 \mathrm{~V}$ ports of the Arduino microcontroller. It can be manufactured in any household at a very low cost and can be installed anywhere be it in offices, educational institutes, public transport, regular shops etc.

To draw a concluding line to the project it can be said that in a war with an invisible enemy the device is a weapon for survival in this pandemic situation.

\section{REFERENCES}

[1]. Public Health Response to the Initiation and Spread of Pandemic COVID-19 in the United States, February 24-April 21, 2020 Weekly / May 8, 2020 / 69(18);551-556 On May 1, 2020, this report was posted online as an MMWR Early Release.Anne Schuchat, MD; CDC COVID-19 Response Team. (https://www.cdc.gov/mmwr/volumes/69/wr/mm6918 e2.htm)

[2]. WORKING PRINCIPLE OF ARDUINO AND USING IT AS A TOOL FOR STUDY AND RESEARCH Leo Louis International Journal of Control, Automation, Communication and Systems (IJCACS), Vol.1, No.2, April 2016

[3]. https://store.arduino.cc/usa/arduino-uno-rev3

[4]. https://www.arduino.cc/en/Tutorial/ping

[5]. https://www.electronicsforu.com/resources/learnelectronics/16x2-lcd-pinout-diagram

[6]. https://www.bc-robotics.com/tutorials/using-a-tmp36temperature-sensor-with-arduino/

[7]. https://learn.adafruit.com/pir-passive-infraredproximity-motion-sensor 